\title{
Forecasting strategies and analyzing the numbers of incoming students: Case in Taiwanese vocational schools
}

\author{
Thanh-Tuyen Tran* \\ Scientific Research Office, Lac Hong University - No.10 Huynh Van Nghe, Bien Hoa, Dong Nai, Vietnam
}

\section{A R T I C LE IN F O}

\section{Article history:}

Received 5 June 2017

Received in revised form

1 August 2017

Accepted 2 August 2017

\section{Keywords:}

Forecasting

GM(1,1)

Moving Average

Grey model

Taiwanese education

Vocational schools

\begin{abstract}
A B S T R A C T
In the past few years, it is transparently observed a strict policy in Taiwan that government always has a tendency to focus on vocational and technical education, which is believed to create positive and miracle changes to their economy. However, to some extent, this trend faces several challenges: excellent courses and supporting facilities, long effective in training workers, are becoming outdated; students are getting less interested in vocational schools; and funding priorities for educational restructuring are still ambiguous. In addition, this thesis uses then Grey System theory is applied for gathering and analyzing these data in the period of 2007 to 2013, which then can be forecasted to 2016, while Moving Average has its own limitations so it is just used to forecast for 2014. Based on the potentials and accuracy of Grey model e.g., Grey model is still able to be applied for short-time forecasting or missing data, this study has finally used this model for further analysis by using its forecasting results. Consequently, the researcher demand for statistical data in term of how these numbers will increase or decrease in near future. As a result, simultaneously, when the downturns go to the "hot" majors, the trend experiences a huge increase in the Home Economics. To be more specific, it is observed a gradual and slight decline with the Marine Products majors. Therefore, this study can clearly provide the Ministry of Taiwanese Education a comprehensive vision so that pragmatic actions regarding education policies and resources allocation will be taken in the future.
\end{abstract}

(C) 2017 The Authors. Published by IASE. This is an open access article under the CC BY-NC-ND license (http://creativecommons.org/licenses/by-nc-nd/4.0/).

\section{Introduction}

According to many previous research studies, Taiwan government recently has always give huge attention to their vocational and technical education. The only reason can explain this policy is because of the significant insufficiency in labor provision, which will be the most influential factor to the economy. However, the ambition to follow this trend has to deal with numerous difficulties in reality. In fact, when students in Taiwan reach a major turning point in their educational careers after graduating from junior high school, they frequently determine their following education approach base upon regional entrance examination scores. Indeed, the best students can attend regular public high schools whilst the others enter vocational or technical schools, or drop out. Both educational tracks have

\footnotetext{
* Corresponding Author.

Email Address: copcoi2@gmail.com

https://doi.org/10.21833/ijaas.2017.09.011

2313-626X/C 2017 The Authors. Published by IASE.

This is an open access article under the CC BY-NC-ND license

(http://creativecommons.org/licenses/by-nc-nd/4.0/)
}

been closely monitored by the government to ensure steady upgrading of the island's labor forces.

To be more specific, the system of vocational and technical education (usually referred to as "VTE" or "vocational programs") played a crucial role with the aim of training this newly urbanized population, facilitating to merge the characteristic features of rural and urban society through a policy of gradual transition sociologists called "urbanization". In conjunction with the new compulsory education requirements, the government also refined its VTE system. At an overall glance, senior vocational schools consist of a three-year curriculum. There are currently twice as many high school age students attending vocational schools as those attending regular senior high schools, indicating the importance placed on VTE training in the ROC. A special consideration should be mentioned is that a total of 212 senior vocational schools provide a selection of 98 specialized courses in eight categories: industry, commerce, home economics, agriculture, nursing and midwifery, marine products, opera and the arts, and medical aide training, according to Taiwan info. 
Therefore, in order to meet the increasing demand for more skilled manpower, Taiwanese educational authorities are spreading more and more opportunities for vocational education and training for the tertiary industries. However, the attemptstrongly requires extensive coordination and cooperation among disctintive departments, a task rarely easy in bureaucracies. On the other side of the fence, the urgent need for workers has generated another dilemma as well-illegal foreign labor. As the working population diversifies into new fields, most people turn out to move away from heavy manual. In addition, the timely import of alien labor may help alleviate the labor shortage in the short run, but the experience of other countries illustrates that new dilemmas will soonly appear afterward. All in all, both the flourish of the VTE program and the process of upgrading structural organization could well be retarded if foreign labor becomes a positive sponsor for labor-intensive industries.

All in all, Taiwan education is an attractive field that the author wants to do a research about it. To have a quality research, the author has looked at Taiwan's education background information and the others old study about it. When doing the research, the author found out that there was a few number of them can clarify the specific numbers of Taiwanese students in vocational school through years. There were two research objectives used to clarify the number off Taiwanese students in the vocational education through years. By using the past data from the main information portal page of Taiwanese Ministry of Education, the transition of the Taiwanese students in the upcoming 4 years can be predicted. Second, the Grey System theory, which is used for analyzing those data from 2007 to 2013, to, predicted the 2016 figures. If the author success to give out the specific predicted indicators which were divided into main majors in the vocational education, universities can have proper strategy for the policy as well as the government. One comparison was added to increase the clarification of the topic. Because there are so few prediction solutions for the numbers in education, so this objective will be useful help to the country education system development in the further future.

\section{Literature review}

\subsection{Fundamental concepts of grey system theory}

To observe and receive an overview about the future value through the past and modern data is what it means by prognostication (Liu et al., 2004). The usage of Grey model is to predict the change of system after examining the combination of clear data and variable information. It means that Grey is used to forecast the time-dependent gradation process of changing in specific area or range (Cheng, 2003). It is also known to estimate the total quantity of Grey forecast model (Nguyen and Tran, 2015). The first step is to generate strong regularity Grey input methods in order to make less randomness on data sequence of the original data flow. In the second step, a range of equation model established is considered with the aim to discover and gain the rule of sequence, also make a prediction of the future trend of current system. Thus, a giant leap is able to be simply achieved to establish the wonted and energetic differential equation through fixed data source (Liu et al., 2004 and Cheng, 2003). All in all, Grey predicting is the most well-known methods to be applied to analyze the consequence of numerical data output from the single time series data (Tang and Feng, 2007).

\subsection{Grey model}

This is a time series forecasting model, which is refreshed as the latest data coming available to the prediction model, and the differential equations of the Grey Model have time-varying coefficients. The Grey Model can only be used in positive data sequences (Deng, 1989). This paper uses grey models to make prediction for the future values of the primitive data points since all the primitive data points are positive. To obtain the n-step ahead predicted value of the system, this research solves the differential equation, Grey Model Lastly, the Inverse Accumulating Generation Operator (IAGO) is applied to search for the predicted values of original data by the predicted value (Nguyen and Tran, 2017).

$X^{(0)}=x^{0}(1), x^{0}(2), x^{0}(3), \ldots, x^{0}(n), n \geq 4$

where $\mathrm{X}^{(0)}$ is a non-negative sequence and $\mathrm{n}$ is the sample size of the data.

When this sequence is subjected to the Accumulating Generation Operation (AGO), the following sequence $X^{(1)}$ is obtained. It is obvious that $\mathrm{X}^{(1)}$ is monotonically increasing.

$$
\begin{aligned}
& X^{(1)}=\left(x^{(1)}(1), x^{(1)}(2), \ldots, x^{(1)}(n)\right), \quad n \geq 4 x^{(1)}(k)= \\
& \sum_{i=1}^{k} x^{(0)}(i), \quad k=1,2,3 \ldots, n
\end{aligned}
$$

The generated mean sequence of $\mathrm{Z}^{(1)}$ of $\mathrm{X}^{(1)}$ is defined as:

$\mathrm{Z}^{(1)}=\left(\mathrm{z}^{(1)}(1), \mathrm{z}^{(1)}(2), \ldots, \mathrm{z}^{(1)}(\mathrm{n})\right)$

where $\mathrm{z}^{(1)}(\mathrm{k})$ is the mean value of adjacent data, i.e., $\mathrm{z}^{(1)}(\mathrm{k})=0.5 \mathrm{x}^{(1)}(\mathrm{k})+0.5 \mathrm{x}^{(1)}(\mathrm{k}-1), \quad \mathrm{k}=2,3, \ldots, \mathrm{n}$

The least square estimate sequence of the grey difference equation of Grey model is defined as follows (Deng, 1989):

$\mathrm{x}^{(0)}(\mathrm{k})+\mathrm{az}{ }^{(1)}(\mathrm{k})=\mathrm{b}$

The whitening equation is therefore, as follows:

$\frac{d x^{1}(t)}{d t}+a x^{1}(t)=b$ 
In above, $[a, b]^{\mathrm{T}}$ is a sequence of parameters that can be seen as follows:

$[\mathrm{a}, \mathrm{b}]^{\mathrm{T}}=\left(\mathrm{B}^{\mathrm{T}} \mathrm{B}\right)^{-1} \mathrm{~B}^{\mathrm{T}} \mathrm{Y}$

$\mathrm{Y}=\left[\mathrm{x}^{(0)}(2), \mathrm{x}^{(0)}(3), \ldots, \mathrm{x}^{(0)}(\mathrm{n})\right]^{\mathrm{T}}$

$\mathrm{B}=\left[\begin{array}{ll}-\mathrm{z}^{(1)}(2) & 1 \\ -\mathrm{z}^{(1)}(3) & 1 \\ \cdot & \cdot \\ \cdot & \cdot \\ \cdot & \cdot \\ -\mathrm{z}^{(1)}(\mathrm{n}) & 1\end{array}\right]$.

The solution of $x^{(1)}(t)$ at time $k$ :

$\mathrm{x}_{\mathrm{p}}^{(1)}(\mathrm{k}+1)=\left[\mathrm{x}^{(0)}(1)-\frac{\mathrm{b}}{\mathrm{a}}\right] \mathrm{e}^{-\mathrm{ak}}+\frac{\mathrm{b}}{\mathrm{a}}$

The IAGO is calculated to show out the following grey model to obtain the predicted value of the primitive data at time $(\mathrm{k}+1)$.

$\mathrm{x}_{\mathrm{p}}^{(0)}(\mathrm{k}+1)=\left[\mathrm{x}^{(0)}(1)-\frac{\mathrm{b}}{\mathrm{a}}\right] \mathrm{e}^{-\mathrm{ak}}\left(1-\mathrm{e}^{\mathrm{a}}\right)$

and the predicted value of the primitive data at time $(\mathrm{k}+\mathrm{H})$ :

$\mathrm{x}_{\mathrm{p}}^{(0)}(\mathrm{k}+\mathrm{H})=\left[\mathrm{x}^{(0)}(1)-\frac{\mathrm{b}}{\mathrm{a}}\right] \mathrm{e}^{-\mathrm{a}(\mathrm{k}+\mathrm{H}-1)}\left(1-\mathrm{e}^{\mathrm{a}}\right)$

\subsection{Previous studies on grey model and its application}

There have been a lot of success and achievements through the grey prediction method. Among all is Lin and Deng (1996) on gas pool prediction. Grey Model oil and natural gas distribution in South China Sea, and the consequent drilling gained success. Grey system model to predict the results of its application and the list goes on, one by one. Technical Zhaowu Fan made forecasting the evolution of the Yellow River estuary terrain; Henan Oilfield Block Professor Pan Helping completion of the Grey clustering analysis; destroy obstacles scheme landed program selection is done by defending the stone; in a grey predictable flow landslides changed by CITIC Jiang, who completed the trend; all of the above by researchers for the development of traditional Chinese medicine, QiuXuejun Grey diagnostic system made effective social and economic benefits (Lin and Deng, 1996).

This method is suitable for the trends of the digits, and also opens a new view for forecasting the problems of human resources related to the numbers mentioned above in Taiwan education system. In fact, the numbers of lecturers and students in Vietnam fluctuate uncertainly due to many complicated reasons, such as education policies, facilities for researching, salary issue, and brain draining in high tech, fluctuated recruiting student numbers, and university locations i.e. many are big cities and vice versa to suburb areas. Therefore, applying this method is reasonable for the research and finding out solutions for the future work of the general management to the education system based on the predicted numbers in the next two years and future.

\section{Case analysis}

\subsection{Data source}

This paper uses the statistics provided by the Taiwanese Ministry of Education. These data were posted in the official website based on the real numbers of total students and lecturers in all Taiwanese universities. Taiwanese government has placed great emphasis on Technological and Vocational Education (TVE), especially in strengthening the ties between TVE and economic development.

As a result, TVE has contributed greatly to Taiwan's economic prosperity over the years. With the government's proactive attention to TVE's development, currently there are 155 senior vocational schools, 14 junior colleges, and 77 universities/colleges of science and technology, totally 246. In the table, the total numbers of students have been arranged separately on the school years including seven kinds including vocational school: Agricultural, Industrial, Commercial, Marine Products, Nursing and Midwifery, Home Economics and others.

After the data are collected (Table 1), this study uses them to have some calculating samples applying grey forecasting developed by Deng (1989).

\subsection{Sample forecasting of grey model}

In this part, a practical forecasting is conducted on the number of students in the Academic years 2007 2013 by adopting the above Grey Model by Deng (1989) (Table 2 and Fig. 1).

\subsection{Accuracy inspection analysis of forecasting ability}

Numerous methods exist for judging forecasting model accuracy, and no single recognized inspection method exists for forecasting ability. Mean Absolute Percentage Error (MAPE) is often used to measure forecasting accuracy (Hyndman and Koehler, 2006; Nguyen et al., 2015).

(MAPE) is measure of accuracy in a fitted time series value in statistics, specifically trending. It usually expresses accuracy as a percentage.

Smaller MAPE value indicates better forecasting ability.

$M A P E=\frac{1}{n} \sum \frac{\mid \text { Actual-Forecast } \mid}{\text { Actual }} \times 100$

$\mathrm{n}$ is forecasting number of step.

Evaluation of MAPE forecasting ability is divided forecasting ability is evaluated as follows:

- $<10 \%$ Excellent forecasting ability

- $10 \% \sim 20 \%$ Good forecasting ability 
- $20 \% \sim 50 \%$ Reasonable forecasting ability

- $>50 \%$ Poor forecasting

In order to ensure that the Grey Forecasting based on MATLAB has high accuracy for application in predicting the number in reality, this part of the research calculates the errors of the process. Table 3 shows the range of these errors from $0.1091 \%$ to $2.1938 \%$, forecasting ability.

Table 1: Numbers of students in vocational schools in Taiwan

\begin{tabular}{|c|c|c|c|c|c|c|c|c|}
\hline \multirow[b]{2}{*}{$\begin{array}{l}\text { School } \\
\text { Year }\end{array}$} & \multicolumn{8}{|c|}{ Vocational School } \\
\hline & Subtotal & Agricultural & Industrial & Commercial & $\begin{array}{c}\text { Marine } \\
\text { Products }\end{array}$ & $\begin{array}{l}\text { Nursing and } \\
\text { Midwifery }\end{array}$ & $\begin{array}{c}\text { Home } \\
\text { Economics }\end{array}$ & Others \\
\hline $1998-99$ & 493055.00 & 18166.00 & 206199.00 & 191523.00 & 7612.00 & 24075.00 & 41590.00 & 3890.00 \\
\hline $1999-2000$ & 467207.00 & 17351.00 & 196304.00 & 181403.00 & 7466.00 & 22574.00 & 38921.00 & 3188.00 \\
\hline 2000-01 & 427366.00 & 15293.00 & 179620.00 & 167646.00 & 7182.00 & 18615.00 & 35961.00 & 3049.00 \\
\hline 2001-02 & 377731.00 & 13495.00 & 159718.00 & 148264.00 & 6336.00 & 14025.00 & 32822.00 & 3071.00 \\
\hline $2002-03$ & 339627.00 & 11387.00 & 145134.00 & 132837.00 & 5335.00 & 9773.00 & 32171.00 & 2990.00 \\
\hline 2003-04 & 325996.00 & 10383.00 & 140347.00 & 127917.00 & 4774.00 & 6576.00 & 33022.00 & 2977.00 \\
\hline 2004-05 & 326159.00 & 9665.00 & 140029.00 & 129895.00 & 4557.00 & 4982.00 & 33673.00 & 3358.00 \\
\hline $2005-06$ & 331604.00 & 9321.00 & 141826.00 & 135571.00 & 4408.00 & 2600.00 & 33886.00 & 3992.00 \\
\hline $2006-07$ & 335554.00 & 9438.00 & 140698.00 & 141253.00 & 3985.00 & 1380.00 & 33981.00 & 4819.00 \\
\hline $2007-08$ & 339497.00 & 9594.00 & 139940.00 & 147618.00 & 3635.00 & -- & 33384.00 & 5326.00 \\
\hline 2008-09 & 346563.00 & 9718.00 & 139893.00 & 155117.00 & 3428.00 & -- & 32739.00 & 5668.00 \\
\hline $2009-10$ & 354608.00 & 9881.00 & 138703.00 & 163973.00 & 3619.00 & -- & 32483.00 & 5949.00 \\
\hline $2010-11$ & 362514.00 & 9868.00 & 138354.00 & 172176.00 & 3642.00 & -- & 32139.00 & 6335.00 \\
\hline $2011-12$ & 366449.00 & 10612.00 & 129116.00 & 123089.00 & 2454.00 & -- & 93976.00 & 7202.00 \\
\hline $2012-13$ & 369436.00 & 10775.00 & 128263.00 & 123486.00 & 2400.00 & -- & 96273.00 & 8239.00 \\
\hline 2013-14 & 360491.00 & 10974.00 & 124580.00 & 117891.00 & 2376.00 & -- & 95648.00 & 9022.00 \\
\hline
\end{tabular}

Table 2: Forecasting results of grey model

\begin{tabular}{ccccc}
\hline Year & k value & Actual value (1) & Forecasted value (2) & Residual error (2-1) \\
\hline 2007 & 1 & 339,497 & 339,497 & 0 \\
2008 & 2 & 346,563 & 351,721 & 5,158 \\
2009 & 3 & 354,608 & 354,995 & 387 \\
2010 & 4 & 362,514 & 358,300 & $-4,214$ \\
2011 & 6 & 366,449 & 361,635 & $-4,814$ \\
2012 & 7 & 369,436 & 365,002 & $-4,434$ \\
2013 & 8 & 360,491 & 368,399 & 7,908 \\
2014 & 9 & -- & 371,829 & -- \\
2015 & 10 & -- & 375,290 & -- \\
2016 & 11 & -- & 378,784 & -- \\
\hline
\end{tabular}

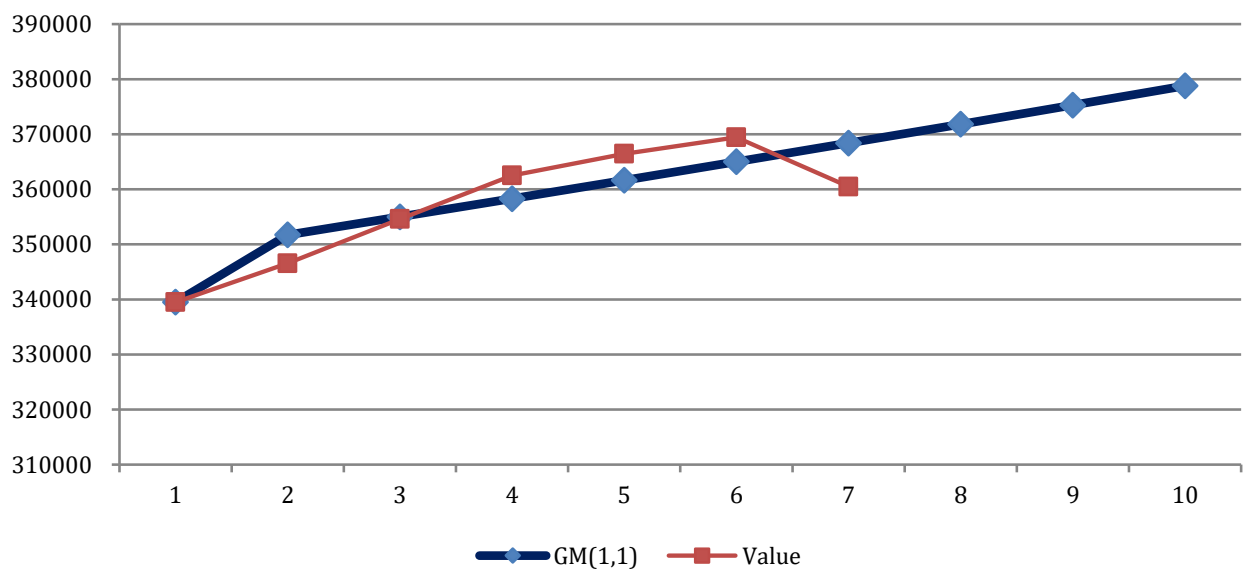

Fig. 1: Graphical forecasting results of grey model

The indexes in the following tables will clearly show that the GM $(1,1)$ and Moving Average models gain high accuracy. Due to the fact that in the Taiwanese vocational schools, it's not easy to have the full assessment of relevant data about its determinants, both GM $(1,1)$ and Moving Average are good models to be considered.

Moreover, based on their MAPE values, it can be concluded that the calculated values based on these two models follow closely to the actual values; while
GM $(1,1)$ is strongly suggested since its relevant indexes in the tables are better, Moving Average demonstrates the trend of vocational students better. Highly precise forecasting result will help the policymakers and related organizations in the Education Management of Taiwan to arrange enough facilities and human resources for the upcoming years and also make regular maintenance and training just for a stable growth of the vocational schools. 
Table 3: The original and prediction values and errors (2007 2013)

\begin{tabular}{cccccc}
\hline Year & Actual value & GM(1,1) & Moving Average & Error $\frac{|(1-2)|}{2} \times 100 \%$ & Error $\frac{|(1-3)|}{2} \times 100 \%$ \\
2004 & 326,159 & -- & -- & -- & -- \\
2005 & 331,604 & -- & -- & -- & -- \\
2006 & 335,554 & -- & -- & $0.00 \%$ & -- \\
2007 & 339,497 & 339,497 & 331,106 & $1.49 \%$ & $2.47 \%$ \\
2008 & 346,563 & 351,721 & 335,552 & $0.11 \%$ & $3.18 \%$ \\
2009 & 354,608 & 354,995 & 340,538 & $1.16 \%$ & $3.97 \%$ \\
2010 & 362,514 & 358,300 & 346,889 & $1.31 \%$ & $4.31 \%$ \\
2011 & 366,449 & 361,635 & 354,562 & $1.20 \%$ & $3.24 \%$ \\
2012 & 369,436 & 365,002 & 361,190 & $2.19 \%$ & $2.23 \%$ \\
2013 & 360,491 & 368,399 & 366,133 & $7.47 \%$ & $1.57 \%$ \\
\multicolumn{7}{c}{ Sums of the ERRORS } \\
\hline \multicolumn{7}{c}{ MAPE }
\end{tabular}

\section{Finding and discussion}

In this section, the calculations on the total numbers of the students in the Taiwanese vocational schools during the recent and future years are mentioned; moreover, prediction values for the 3 school years 2014 to 2016 are typically focused.

\subsection{Total students in Taiwanese vocational schools}

The following grey prediction Grey model estimates total numbers are raising from 368399 in
2013 to 378784 in 2016, respectively. The forecasting errors are ranging from only $0.00 \%$ to 2.1938\%, which indicates excellent predicting ability of Grey model. The Moving Average on the other hand, demonstrates good trend when it forecasts this number will be downturn (just as the original one moving) (Table 4 and Fig. 2).

Fig. 3 shows the steadily growth of the total students pursuing the undergraduate programs in Taiwan. Through the 9-year time (2007 to 2016), this trend slightly is about over 40,000 students totally, as forecasted.

Table 4: The total numbers of students in vocational school as predicted

\begin{tabular}{|c|c|c|c|c|c|}
\hline Values School Years & Original (1) & GM Prediction (2) & MA Prediction (3) & Error of GM & Error of MA \\
\hline 2007 & 339,497 & 339497 & 331,106 & $0.00 \%$ & $2.47 \%$ \\
\hline 2008 & 346,563 & 351721 & 335,552 & $1.49 \%$ & $3.18 \%$ \\
\hline 2009 & 354,608 & 354995 & 340,538 & $0.11 \%$ & $3.97 \%$ \\
\hline 2010 & 362,514 & 358300 & 346,889 & $1.16 \%$ & $4.31 \%$ \\
\hline 2011 & 366,449 & 361635 & 354,562 & $1.31 \%$ & $3.24 \%$ \\
\hline 2012 & 369,436 & 365002 & 361,190 & $1.20 \%$ & $2.23 \%$ \\
\hline 2013 & 360,491 & 368399 & 366,133 & $2.19 \%$ & $1.57 \%$ \\
\hline 2014 & & 371829 & 365,459 & & \\
\hline 2015 & & 375290 & & & \\
\hline 2016 & & 378784 & & & \\
\hline \multicolumn{4}{|c|}{ MAPE } & $1.07 \%$ & $3.00 \%$ \\
\hline
\end{tabular}

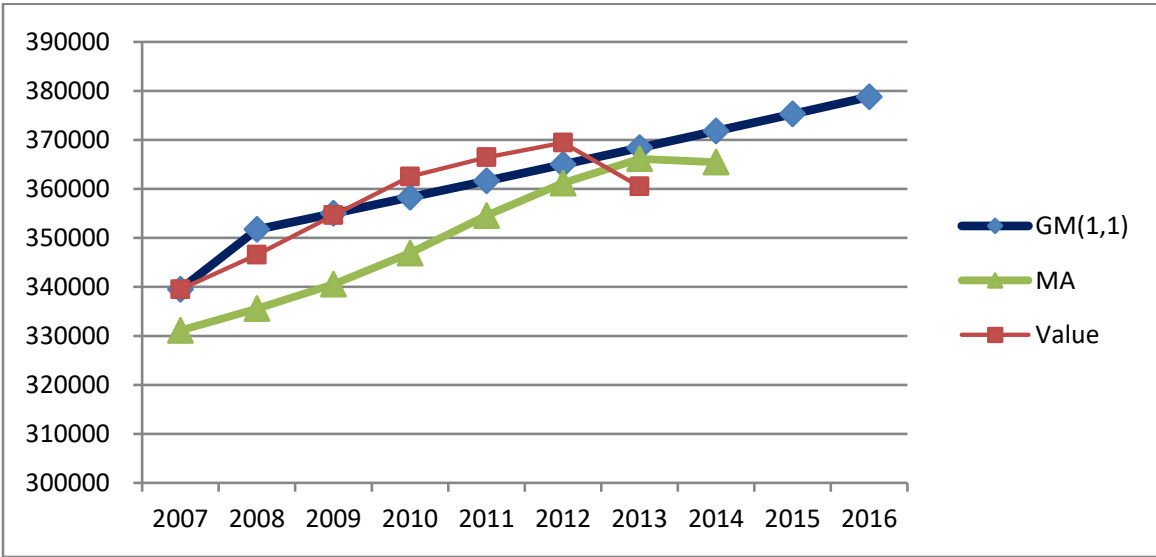

Fig. 2: The sequence step of the numbers of students as predicted

\subsection{The numbers of students in agricultural of vocational schools}

Table 5 and Fig. 3 indicate a steady increase in numbers year by year. The prediction results for next 3 years are: 11313; 11622; and 11940. We also notice the prediction errors which are ranged from only $0.04 \%$ to $2.91 \%$, and $1 \%$ to $5 \%$ of Moving Average interpreted good results.

\subsection{The numbers of students in Industrial majors of vocational schools}

The trend is becoming 'decrease' after the long period. Apparently, we can recognize in the line 
graph, which is in the future at 115924 (2016) compared with 139940 (2007). The forecasting errors are low (around 0.5\%), which is interpreted to be an excellent (Table 6 and Fig. 4).

Table 5: The numbers of students in agricultural of vocational schools as predicted

\begin{tabular}{cccccc}
\hline Values School Years & Original (1) & GM Prediction (2) & MA Prediction (3) & Error of GM & Error of MA \\
\hline 2007 & 9,594 & 9594 & 9474 & $0.00 \%$ & $1.24 \%$ \\
2008 & 9,718 & 9621 & 9451 & $0.99 \%$ & $2.75 \%$ \\
2009 & 9,881 & 9885 & 9583 & $0.04 \%$ & $3.01 \%$ \\
2010 & 9,868 & 10155 & 9731 & $2.91 \%$ & $1.39 \%$ \\
2011 & 10,612 & 10433 & 9822 & $1.69 \%$ & $7.44 \%$ \\
2012 & 10,775 & 10718 & 10120 & $0.53 \%$ & $6.08 \%$ \\
2013 & 10,974 & 11011 & 104183 & $0.34 \%$ & $5.06 \%$ \\
2014 & 11313 & 10787 & & \\
2015 & 11622 & & & \\
2016 & & 11940 & & $0.93 \%$ & $3.85 \%$ \\
\hline
\end{tabular}

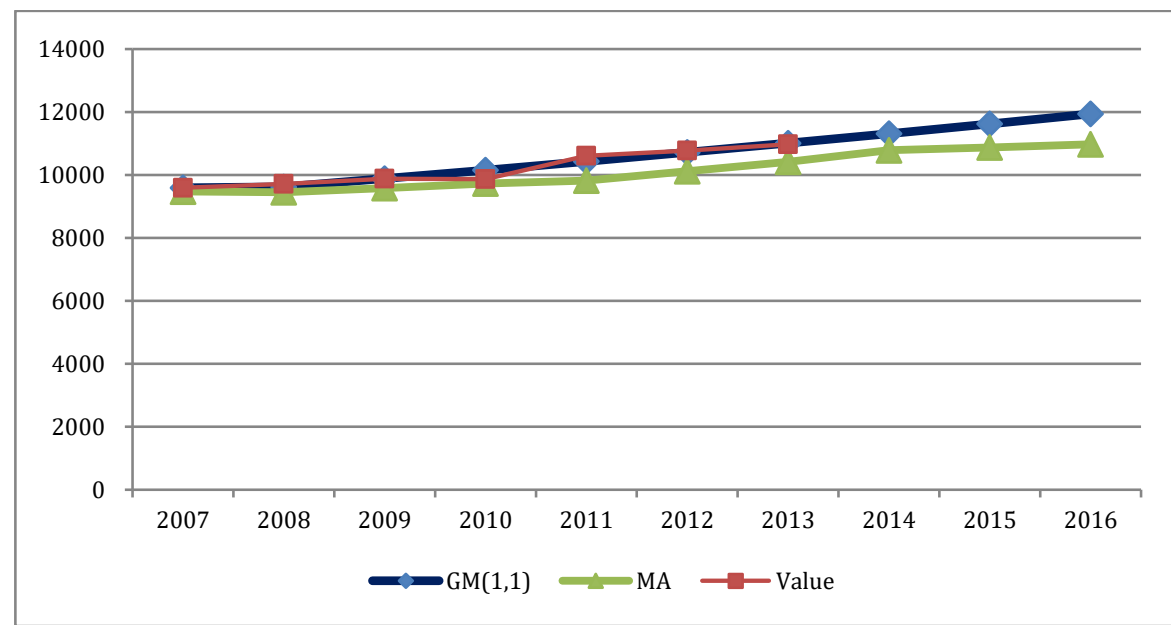

Fig. 3: The sequence step of the numbers of students in agricultural of vocational schools as predicted

Table 6: The numbers of students in industrial of vocational schools as predicted

\begin{tabular}{cccccc}
\hline Values School Years & Original (1) & GM Prediction (2) & MA Prediction (3) & Error of GM & Error of MA \\
\hline 2007 & 139,940 & 139940 & 140851 & $0.00 \%$ & $0.6510 \%$ \\
2008 & 139,893 & 141610 & 140821 & $1.23 \%$ & $0.6636 \%$ \\
2009 & 138,703 & 138112 & 140177 & $0.43 \%$ & $1.0627 \%$ \\
2010 & 138,354 & 134699 & 139512 & $2.64 \%$ & $0.8370 \%$ \\
2011 & 129,116 & 131371 & 138983 & $1.75 \%$ & $7.6422 \%$ \\
2012 & 128,263 & 128125 & 135391 & $0.11 \%$ & $5.5573 \%$ \\
2013 & 124,580 & 124960 & 131911 & $0.30 \%$ & $5.8846 \%$ \\
2014 & 121872 & 127319 & & \\
2015 & 118861 & & & \\
2016 & \multicolumn{7}{c}{ MAPE } \\
\multicolumn{7}{c}{} \\
\hline
\end{tabular}

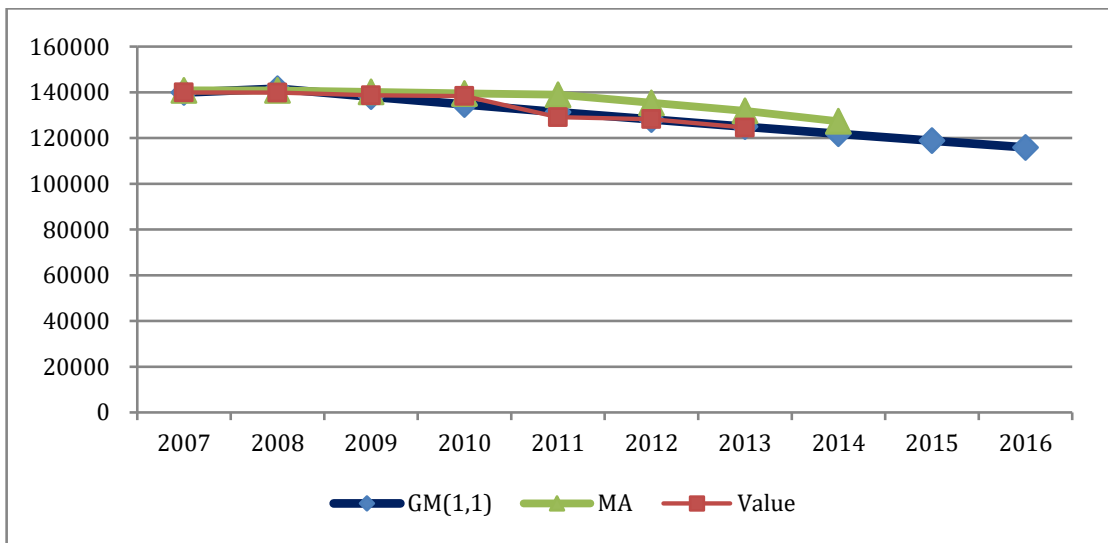

Fig. 4: The sequence step of the numbers of students in industrial of vocational schools predicted

\subsection{The numbers of students in commercial majors of Vocational Schools}

Table 7 shows a significant decline in the numbers of Taiwanese students who pursue
Commercial Education of Vocational School in the past-present-future time. The future numbers are 111182 students in 2014; 103751 in 2015; and 96816 in 2016. The decreasing gap will be approximately estimated about more than 20 
thousand students for each future year. The line graph in Fig. 5 also illustrates the downward trend. The forecasting errors are very low (around 8\%), which indicate the method used in the paper is doing a very good job for the future numbers.

Table 7: The numbers of students in commercial of vocational schools as predicted

\begin{tabular}{|c|c|c|c|c|c|}
\hline Values School Years & Original (1) & GM Prediction (2) & MA Prediction (3) & Error of GM & Error of MA \\
\hline 2007 & 147,618 & 147618 & 135573 & $0.00 \%$ & $8.16 \%$ \\
\hline 2008 & 155,117 & 168387 & 141480 & $8.55 \%$ & $8.79 \%$ \\
\hline 2009 & 163,973 & 157132 & 147996 & $4.17 \%$ & $9.74 \%$ \\
\hline 2010 & 172,176 & 146628 & 155569 & $14.84 \%$ & $9.65 \%$ \\
\hline 2011 & 123,089 & 136827 & 163755 & $11.16 \%$ & $33.04 \%$ \\
\hline 2012 & 123,486 & 127681 & 153079 & $3.40 \%$ & $23.96 \%$ \\
\hline 2013 & 117,891 & 119147 & 139583 & $1.07 \%$ & $18.40 \%$ \\
\hline 2014 & & 111182 & 121488 & & \\
\hline 2015 & & 103751 & & & \\
\hline 2016 & & 96816 & & & \\
\hline \multicolumn{4}{|c|}{ MAPE } & $6.17 \%$ & $15.96 \%$ \\
\hline
\end{tabular}

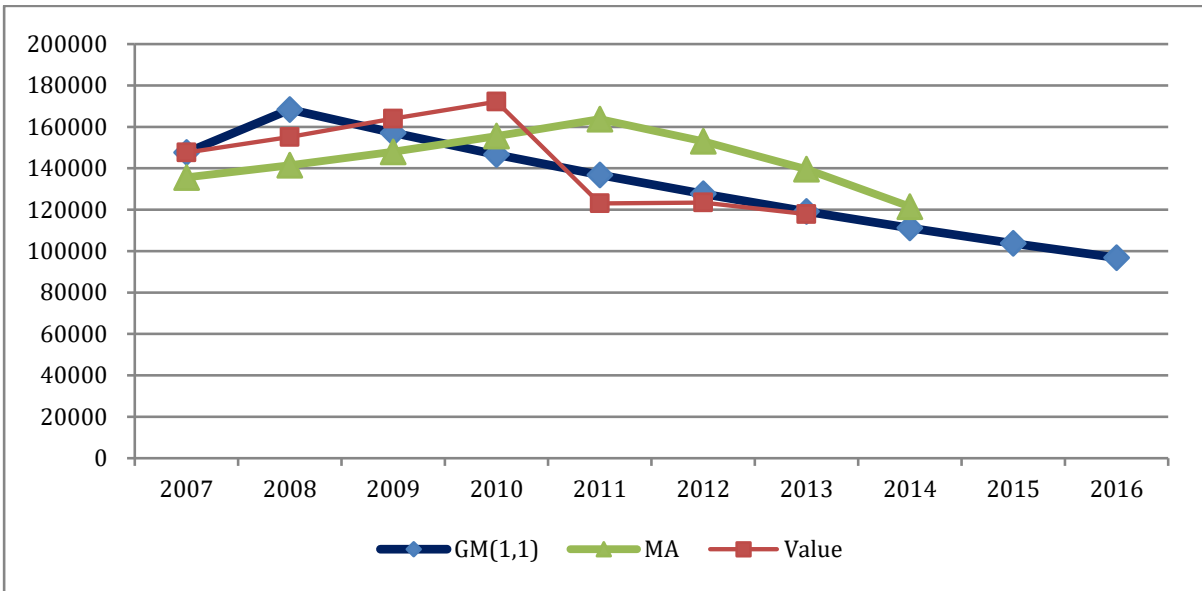

Fig. 5: The sequence step of the numbers of students in commercial of vocational schools predicted

\subsection{The numbers of students in marine products majors of Vocational Schools}

In Table 8, Grey model gives us the forecasting numbers of Taiwanese students who are studying Marine Products of Vocational Schools in 2014, 2015, and 2016 and the future numbers for these future years will be 2120; 1930; and 1756, respectively. The line graph in Fig. 6 shows a downward trend in numbers for the next four years. In the future, the numbers of students in this major will steadily decrease for more than one thousands of students per year. The residual errors of forecasting are ranging from only $1 \%$ to $15 \%$ show excellent forecasting ability. Moreover, the trend should be stable according Moving Average which is not performed in Grey model.

\subsection{The numbers of students in home economics majors of vocational schools}

Table 9 shows the prediction numbers of Taiwanese students who will enroll Home Economics of Vocational Schoolsin the next 3 years. The forecasted numbers will be 139863 in 2014; 178109 in 2015; and 226813 in 2016. The most important aspect of a home economics education is that students not only learn about subject matter that has relevance to their present lives, but will constantly be of use as they continue to grow (McIntosh et al., 2009).

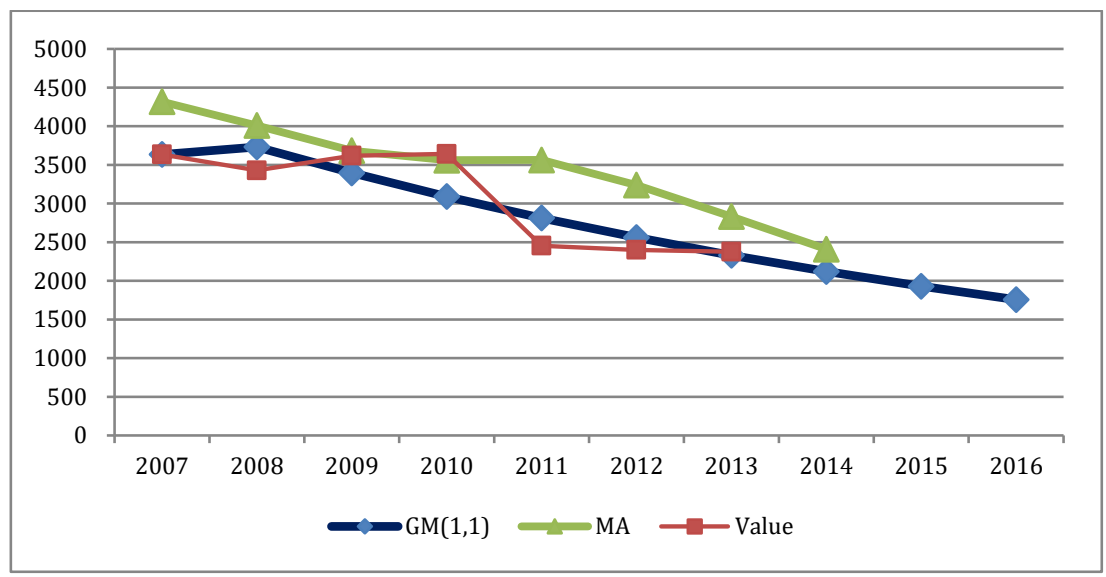

Fig. 6: The sequence step of the numbers of students in marine products of vocational schools predicted 
Table 8: The numbers of students in marine products of vocational schools as predicted

\begin{tabular}{cccccc}
\hline Values School Years & Original (1) & GM Prediction (2) & MA Prediction (3) & Error of GM & Error of MA \\
\hline 2007 & 3,635 & 3635 & 4316 & $0.00 \%$ & $18.75 \%$ \\
2008 & 3,428 & 3731 & 4009 & $8.84 \%$ & $16.96 \%$ \\
2009 & 3,619 & 3396 & 3682 & $6.17 \%$ & $1.76 \%$ \\
2010 & 3,642 & 3091 & 3560 & $15.14 \%$ & $2.23 \%$ \\
2011 & 2,454 & 2813 & 3563 & $14.62 \%$ & $45.19 \%$ \\
2012 & 2,400 & 2560 & 3238 & $6.67 \%$ & $34.93 \%$ \\
2013 & 2,376 & 2330 & 2832 & $1.94 \%$ & $19.19 \%$ \\
2014 & & 2120 & 2410 & & \\
2015 & & 1930 & & & \\
2016 & & 1756 & & $7.63 \%$ & $19.35 \%$ \\
\hline
\end{tabular}

In Fig. 7, it is clear to observe that the upward trend in numbers of Taiwanese students who will be in Home Economics of Vocational Schools. The predicted numbers of them will gradually increase, and the estimated increasing number is nearly 40 thousand per school year. The errors of the prediction process here are appropriately acceptable at $20 \%$.

Table 9: The numbers of students in home economics of vocational schools as predicted

\begin{tabular}{cccccc}
\hline Values School Years & Original (1) & GM Prediction (2) & MA Prediction (3) & Error of GM & Error of MA \\
\hline 2007 & 33,384 & 33384 & 33846 & $0.00 \%$ & $1.39 \%$ \\
2008 & 32,739 & 32795 & 33750 & $0.17 \%$ & $3.09 \%$ \\
2009 & 32,483 & 41762 & 33368 & $28.57 \%$ & $2.72 \%$ \\
2010 & 32,139 & 53182 & 32868 & $65.48 \%$ & $2.27 \%$ \\
2011 & 93,976 & 67725 & 32453 & $27.93 \%$ & $65.47 \%$ \\
2012 & 96,273 & 86245 & 52866 & $10.42 \%$ & $45.09 \%$ \\
2013 & 95,648 & 109829 & 74129 & $14.83 \%$ & $22.50 \%$ \\
2014 & \multicolumn{7}{c}{139863} & 95299 & & \\
2015 & \multicolumn{7}{c}{ MAPE } \\
2016 & \multicolumn{7}{c}{226813} & & $21.06 \%$ & $20.36 \%$ \\
\hline
\end{tabular}

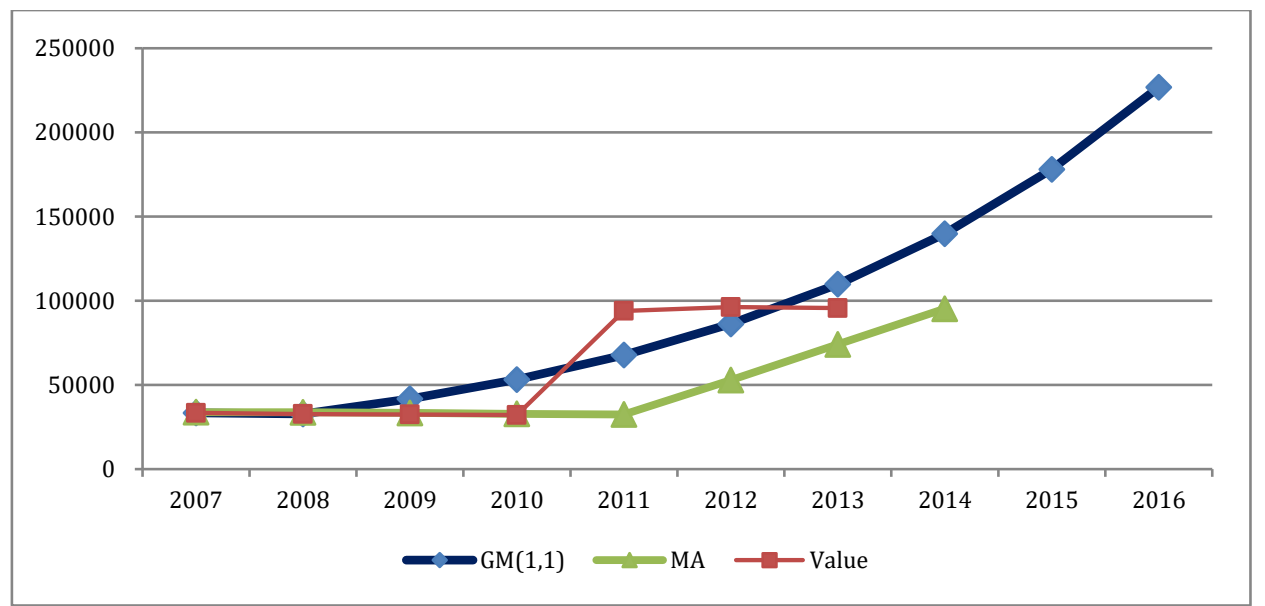

Fig. 7: The sequence step of the numbers of students in home economics of vocational schools as predicted

\subsection{The numbers of students in others majors of vocational schools}

Table 10 reveals the predicted values for the group of Taiwanese students follow Others Majors of Vocational Schools. The numbers of these students are forecasted to have 9908 in 2014; 10964 in 2015; and 12132 in 2016 . These digits are better in Moving Average, because its trending is better than the linear forecasting of Grey model. Moreover, the original numbers have fluctuated wildly recently, and it can only be predicted to be smooth in recent 3 years and 3 years in the future.

Fig. 8 shows the numbers of Taiwanese students register Others Majors of Vocational Schools that will fall into an increase in the next 03 future years.

\subsection{Trending}

Figs. 9 and 10 illustrate the trends of Taiwanese students in Vocational Schools in recent years. Most of students want to take the Industrial and Commercial majors in their vocational programs with the percentages of $41.22 \%$, and $43.48 \%$ in their school years 2007-08, but this trend is downwards.

When the downturns go to the "hot" majors, the trend is going up with the Home Economics. This major sees the jump in the percentage of total students; these percentages are $7.3019 \%$ to $17.0549 \%$ (Fig. 10 and Table 11). This is impressive move.

The change is gradual and slight decline with the Marine Products majors, which was recorded percentages in the year 2007-08 at 1.07\%; and in 
2013-14, it was $0.66 \%$. It is also predicted to have $0.38 \%$ in three years later results combined between two forecasting models.

Table 10: The numbers of students in others majors of vocational schools as predicted

\begin{tabular}{|c|c|c|c|c|c|}
\hline Values School Years & Original (1) & GM Prediction (2) & MA Prediction (3) & Error of GM & Error of MA \\
\hline 2007 & 5,326 & 5326 & 4056 & $0.00 \%$ & $23.84 \%$ \\
\hline 2008 & 5,668 & 5398 & 4712 & $4.77 \%$ & $16.86 \%$ \\
\hline 2009 & 5,949 & 5973 & 5271 & $0.40 \%$ & $11.40 \%$ \\
\hline 2010 & 6,335 & 6609 & 5647 & $4.32 \%$ & $10.85 \%$ \\
\hline 2011 & 7,202 & 7313 & 5984 & $1.54 \%$ & $16.91 \%$ \\
\hline 2012 & 8,239 & 8092 & 6495 & $1.78 \%$ & $21.16 \%$ \\
\hline 2013 & 9,022 & 8954 & 7258 & $0.75 \%$ & $19.54 \%$ \\
\hline 2014 & & 9908 & 81543 & & \\
\hline 2015 & & 10964 & & & \\
\hline 2016 & & 12132 & & & \\
\hline \multicolumn{4}{|c|}{ MAPE } & $1.94 \%$ & $17.22 \%$ \\
\hline
\end{tabular}

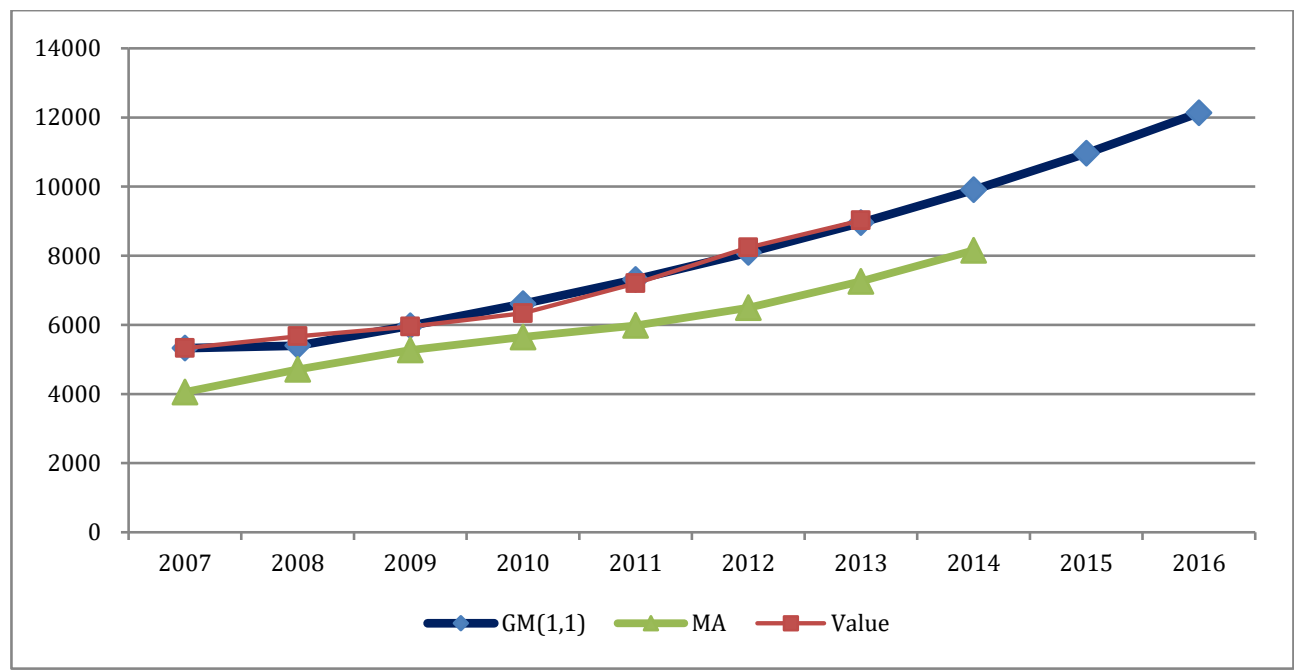

Fig. 8: The sequence step of the numbers of students in others majors of vocational schools predicted

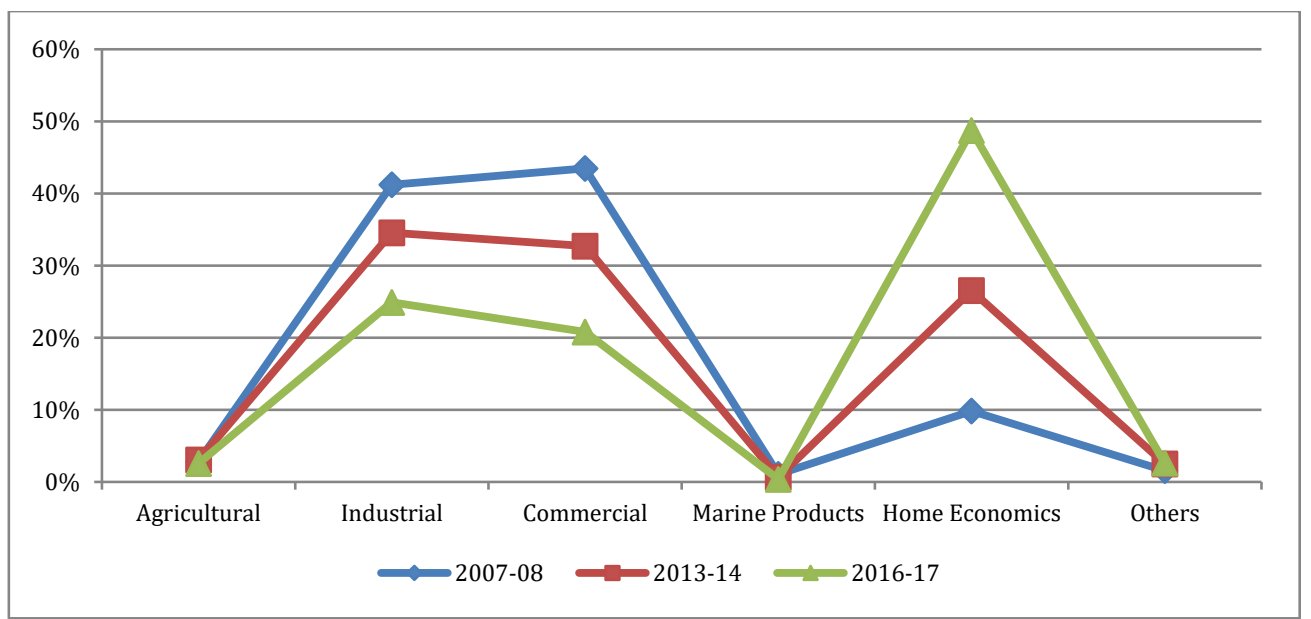

Fig. 9: Summary of learning trends in recent years

\section{Conclusion and discussion}

The results are listed, there is shown a stable trend to predict numbers. Relying on the meaning of each number is concerned that the views of the Taiwan people to influence the development of the scale of Taiwan around the educational structure of the main factors vocational schools and adult education in the society, while the population structure of society, social employment structure and level of economic development is relatively minor.

After the further analysis of these indexes, we can find out some important discussion.
1. It is shown that the demand of Taiwanese society towards the well-trained or the high-levelskilled people is rising up based on the education structure of society, so that day by day more nonschool-age faculty with not-high-levels of education will make decision on accepting vocational education to get the improvement in their educational level and meet the social requirements.

2. The growing income of most of residents is one more reason for top priority of the investment in education and training their skillful jobs.

3. The demographic structure, the working environment structure of society and the developing economy review the quick growth of Taiwanese 
society and economy from the macroscopic view. Such development takes no doubt a good part in the development of tertiary education in Taiwan.

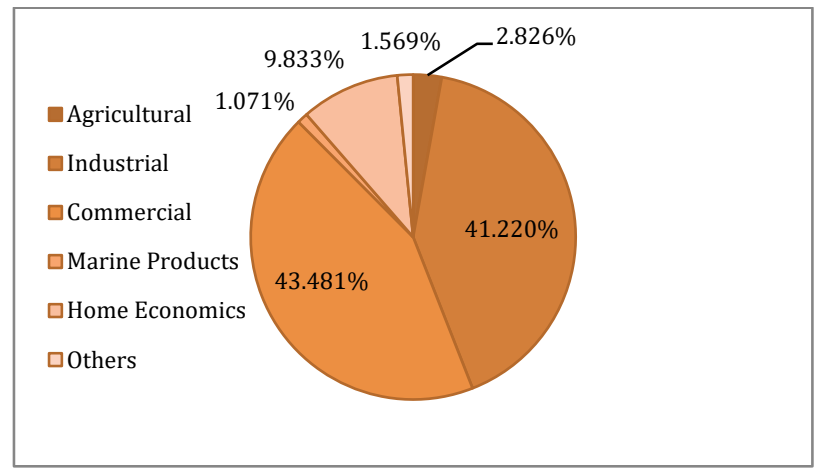

Fig. 10: Percentages of students by discipline in 2007-08

Table 11: Percentages of learning trends past to future by

\begin{tabular}{cccc}
\multicolumn{5}{c}{ GM $(1,1)$} & & \\
\hline Disciplines & $2007-08$ & $2013-14$ & $2016-17$ \\
\hline Agricultural & $2.83 \%$ & $3.04 \%$ & $2.57 \%$ \\
Industrial & $41.22 \%$ & $34.56 \%$ & $24.91 \%$ \\
Commercial & $43.48 \%$ & $32.70 \%$ & $20.80 \%$ \\
Marine Products & $1.07 \%$ & $0.66 \%$ & $0.38 \%$ \\
Home Economics & $9.83 \%$ & $26.53 \%$ & $48.74 \%$ \\
Others & $1.57 \%$ & $2.50 \%$ & $2.61 \%$ \\
\hline
\end{tabular}

To solve the problem of quantity and quality in the vocational education should be based on the new ways of thinking and application of the new training technology.

In the recent 7 years, the total number of students has increased slightly - from 339,497 in 2007 to 360,491 in 2013 , especially the pace has become a little faster in the next three years at 378,784 in 2016.

The above figures make some education managers worried. The issue of managing quantity is in place a harsh and it is reflected more on the public opinion. Moreover, Taiwan's working age population (age 15 to 64) will reach its peak of 17.37 million in 2015 and then steadily decline, Huang et al. (2013) said. The report said Taiwan became an aging society
-- in which people 65 or older account for at least 7 percent of the population -- in 1993, and will become an aged society (14 percent) in 2016 and a superaged society ( 20 percent) in 2025 , according to the estimate

\section{References}

Cheng CC (2003). Forecasting the benefit of a university based on the grey model. Journal of Nanjing Institute of Technology (Natural Science Edition), 1(1): 59-66.

Deng J (1989). Introduction to grey system Theory. The Journal of Grey System, (1)1: 1-24.

Huang CM, Lin LF, Lee TC, and Guo JL (2013). Proximal to distal correlates of the patterns of illicit drug use among night school students in Taiwan. Addictive Behaviors, 38(1): 14811484.

Hyndman RJ and Koehler AB (2006). Another look at measures of forecast accuracy. International Journal of Forecasting, 22(4): 679-688.

Lin CR and Deng JL (1996). On grey prediction of gas pool. New Developments in Grey Systems Research, HUST Press, Wuhan, China.

Liu S, Dang Y, Fang Z, and Xie NM (2004). Grey system theory and its application. Science Press, Beijing, China.

McIntosh J, Collins E, and Collins C (2009). Home economics futures: Possible scenarios and where they take us. International Journal of Home Economics, 2(2): 85-101.

Nguyen NT and Tran TT (2015). Mathematical development and evaluation of forecasting models for accuracy of inflation in developing countries: A case of Vietnam. Discrete Dynamics in Nature and Society. 2015: Article ID 858157, 14 pages. https://doi.org/10.1155/2015/858157

Nguyen NT and Tran TT (2017). Optimizing mathematical parameters of Grey system theory: an empirical forecasting case of Vietnamese tourism. Neural Computing and Applications: 1-15. https://doi.org/10.1007/s00521-0173058-9

Nguyen NT, Tran TT, Wang CN, and Nguyen NT (2015). Optimization of strategic alliances by integrating DEA and grey model. Journal of Grey System, 27(1): 38-56.

Tang QY and Feng MG (2007). DPS data processing systemexperimental design, statistical analysis and data mining. Science Press, Beijing, Chinese. 